\title{
Anthropometric Indices as Indicators of Obesity of Children from Elementary School in Montenegro
}

\author{
Pavle Malovic ${ }^{1}$ \\ ${ }^{1}$ University of Montenegro, Faculty for Sport and Physical Education, Niksic, Montenegro
}

\section{Abstract}

The aim of this research was to determine anthropometric indices as indicators of obesity of children in Montenegro. The research involved 135 children from Montenegro and sample of examinees is divided into two sub-samples. The first sub-sample of the examinees consisted of 66 boys aged 7-8 years from Nikšić and Kotor, while the other sub-sample consisted of 69 girls also aged 7-8 years from Niksic and Kotor. Anthropometric characteristics were evaluated by a battery of 4 variables: body height, body weight, waist and hip circumference. Mentioned variables were used to calculate following anthropometric indices which gave as informations about obesity: Body mass index (BMI), waist-to-hip ratio (WHR), waist-to-height ratio (WHtR). The standard central and dispersive parameters of all variables are calculated. The significance of the differences between the children in the ratios was determined by at-testfor small independent samples. It was not found that the children with different gender have statistically significant differences in analyzed ratios as indicators of obesity. Thus, it was found that $16.3 \%$ of children were obese and those results will help us to realize that we have to adequately affect on detected problem.
\end{abstract}

Key words: Children, Obesity, Montenegro

\section{Uvod}

Još 1997. godine, prema saopštenju Svjetske zdravstvene ogranizacije (WHO), gojaznost je okarakterisana kao javni zdravstveni problem. U saopšetenju se navodi da je uticaj gojaznosti toliko veliki i ekstreman da bi ga trebalo smatrati jednim od najvećih zapostavljenih zdravstvenih problema našeg vremena, a negativan uticaj na zdravlje poredi se čak sa onim koje prouzrokuje pušenje. Povećanje gojaznosti kod đece uočeno je kako u razvijenim zemljama, tako i u zemljama u razvoju (Wang \& Lobstein, 2006). Nedavni izvještaji ukazuju da je ovaj porast mnogo veći u zemljama u razvoju, nego što je to u razvijenim zemljama (de Onis, Blossner, \& Borghi, 2010). Ukoliko je gojaznost prisutna u ranom djetinjstvu postoji tendencija da dijete ima problem sa gojaznošću i tokom daljeg odrastanja, sa rizikom od ranog obolijevanja od hronično nezaraznih bolesti, kao što su dijabetes, povišen krvni pritisak i koronarna arterijska bolest. (Lobstein, Baur, \& Uauy, 2004; de Onis i sar., 2010; Popović, Bjelica, Mašanović, \& Vukotić, 2018). Štaviše, gojazna đeca su pod rizikom od kožnih oboljenja, ortopedskih komplikacija i psihosocijalnih problema kao što su zadirkivanje, odbijanje vršnjaka i depresija (Lobstein i sar., 2004). Takođe, u Sjevernoj Americi i Evropi je zapažen sve veći porast gojaznosti đece poslednje dvije decenije (Gortmaker, Dietz, Sobol, \& Wehler, 1987). Ovo zapažanje izaziva ozbiljnu zabrinutost, a upravo iz razloga što se gojaznost koja se pojavila tokom djetinjstva može zadržati i tokom odrastanja (Power, Lake, \& Cole, 1997; Must, Jacques, Dallal, Bajema, \& Dietz, 1992), što kasnije može prouzrokovati ozbiljna oboljenja u odrasloj dobi, kao što su ateroskleroza i povećani kardiovaskularni morbiditet (Srinivasan, Bao, Wattigney, \& Berenson, 1996). U zemljama sa srednjim i niskim dohotkom gojaznost i neuhranjenost su čest problem (Wang \& Lobstein, 2006). Dakle, u zemljama sa pomenutim nivoom dohotka problem, sa prekomjernom težinom i gojaznošću uglavnom je povezan sa neuhranjenošću u toku fetalnog perioda i prve dvije godine života (Palloni, McEniry, Davila, \& Gurucharri, 2005; Fung, 2009). Epidemiološke studije u nekim od ovih zemalja pokazale su da đeca koja su bila neuhranjena i nedovoljno razvijena imaju veće šanse za nakupljanje masnog tkiva u centralnoj (abdominalnoj) regiji i razvoja metaboličkih

\section{Correspondence:}

\section{Montenegro}

Sport
P. Malovic

University of Montenegro, Faculty for Sport and Physical Education, Narodne omladine bb, 81400 Niksic, Montenegro

E-mail: pavle.m@ucg.ac.me 
komplikacija u kasnijem životu (Schroeder, Martorell, \& Flores, 1999; Gigante, Victora, Horta, \& Lima, 2007; Uauy, Kain, \& Corvalan, 2011; Bjelica, 2006). Praćenje antropometrijskih promjena u populaciji može biti ključno u sprečavanju budućih problema javnog zdravlja, kao što je gojaznost (Popovic, Bjelica, Vukotic, \& Masanovic, 2018; Masanovic, Vukotic, Bjelica, \& Popovic, 2018). Istraživanja ovog tipa mogu pomoći u objašnjavanju važnih uloga obrazovanja i fizičke aktivnosti mladih u prevenciji negativnih zdravstvenih ishoda povezanih sa adipozitetom. Iz svega navedenog, jasno se može zaključiti da je gojaznost široko rasprostranjena u cijelom svijetu, pa samim tim bi se trebalo osvrnuti i na našu zemlju, kao zemlju u razvoju, i napraviti presjek stanja na određenom uzorku ispitanika, u ovom slučaju đece uzrasta 7 i 8 godina, koji odrastaju u centralnom i južnom dijelu, odnosno regionu Crne Gore. S obzirom na navedeno, $u$ ovoj studiji će se, na osnovu upotrebe određenih antropometrijskih indeksa, utvrditi distribucija tjelesne masti i stepen uhranjenosti, odnosno gojaznosti kod pomenutog uzorka ispitanika. Nakon sprovedenog istraživanja dobiće se validni podaci na osnovu kojih će moći da se iznesu određeni zaključci, daju smjernice za dalja istraživanja i ukaže na limitiranost sprovedene studije.

\section{Metod}

U pogledu vremenske određenosti istraživanje je transverzalnog karaktera, a sastoji se u jednokratnom mjerenju odgovarajućih antropometrijskih karakteristika đece uzrasta 7-8 godina koji žive i pohađaju osnovnu školu u Centralnoj (Nikšiču) i Južnoj (Kotoru) regiji Crne Gore. Ukupan broj ispitanika je 135. Svi ispitanici su podijeljeni na dva subuzorka. Prvi subuzorak je činilo 66 učenika Osnovne škole "Ratko Žarić" iz Nikšića i Osnovne škole "Savo Ilić” iz Kotora, dok je drugi subuzorak činilo 69 učenica Osnovne škole "Ratko Žarić" iz Nikšića i Osnovne škole "Savo Ilić" iz Kotora.

Antropometrijsko mjerenje je sprovedeno uz poštovanje osnovnih pravila i principa vezanih za izbor mjernih instrumenata i tehnike mjerenja koji su standardizovani prema uputstvima Internacionalnog Biološkog Programa. Za potrebe ovog istraživanja izmjerene su sljedeće antropometrijske varijable: tjelesna visina (ATV), tjelesna masa (ATM), obim struka (AOS), obim kukova (AOK). Pomenute antropometrijske mjere upotrijebljenje su kako bi bili određeni sljedeći odnosi tjelesne kompozicije i proporcije: indeks tjelesne mase (BMI), odnos opsega struka i kukova (WHR) i odnos struka i visine (WHtR).

Za mjerenje antropometrijskih karakteristika korišćeni su antropometar i digitalna vaga. Prema smjernicama Nacionalnog Centra za Zdravstvenu Statistiku/Svjetske Zdravstvene Organizacije (NCHC/WHO) za procjenu prekomjerne težine i gojaznosti korišćen je indeks tjelesne mase - BMI (World Health Organization expert committee, 1995). BMI svakog đeteta je izračunat tako što se tjelesna težina podijelila sa kvadratom visine $\left(\mathrm{Kg} / \mathrm{m}^{2}\right)$, a nakon toga upoređen sa referentnim vrijednostima za uzrast i pol. Indeks tjelesne mase (BMI) za đecu i mlade osobe se izračunava u zavisnosti od starosti i pola, što je veoma specifično zbog njihovog rasta i razvoja (Vasiljevic, Bjelica, Popovic, \& Gardasevic, 2015). Prilikom procijene stepena uhranjenosti, smatralo se da je učenik/ca u kateogiriji ispod normalne uhranjenosti ukoliko su vrijednosti iznosile ispod 5. percentila, normalne uhranjenosti ukoliko su vrijednosti iznosile od 5. do 85 . percentila, dok su u kategoriji za prekomjernu težinu uračunati oni kojima je BMI iznosio za njihov uzrast i pol $>85$., a $\leq 95$. percentila, na kraju, gojaznost je ustanovljena ukoliko je vrijednost prelazila 95. percentil. Odnos struka i kukova (WHR) za đecu je značajan indikator distribucije masti, naročito abdominalne masti i dobar indikator za procjenu zdravstvenog rizika, a izračunava se tako što se vrijednost obima struka podijeli sa vrijednosti obima kuka. Vrijednosti ovog odnosa za muškarce 1 , za žene 0.8 uzimaju se kao donje granične vrijednosti za procjenu gojaznosti. Vrijednosti preko datog normativa ukazuju na rizik od oboljenja koje su vezane sa prekomjernom težinom i gojaznošću. Odnos struka i visine (WHtR) dobijen je dijeljenjem vrijednosti obima struka sa vrijednostima tjelesne visine. Dijete se smatralo da je gojazno ukoliko je WHtR iznosio više od 0.5 (McCarthy, \& Ashwell, 2006).

Svi podaci potrebni za ovo istraživanje obrađeni su u specijalizovanom programu za obradu podataka IBM SPSS statistics 23. Podaci su obrađeni postupcima deskriptivne i komparativne statističke procedure. Razlike u tjelesnim parametrima za procjenu stepena uhranjenosti, odnosno gojaznosti, učenika uzrasta 7 i 8 godina iz Nikšića i Kotora, utvrđene su primjenom diskriminativnih parametrijskih procedura i primjenom t-testa za male nezavisne uzorke, sa statističkom značajnošću od $\mathrm{p}<0.05$.

\section{Rezultati}

U tabelama su prikazani osnovni deskriptivni statistički parametri prediktora gojaznosti učenika, đe su izračunate sljedeće vrijednosti mjera centralne i disperzione tendencije: aritmetička sredina (Mean) i standardna devijacija (Std. Dev.).

Tabela 1. Raspodjela indeksa tjelesne mase po polu đece

\begin{tabular}{lcccccc}
\hline BMI & \multicolumn{2}{c}{ M } & \multicolumn{3}{c}{ F } & \multicolumn{2}{c}{ Total } \\
\hline Percentile & $\mathrm{N}$ & $\%$ & $\mathrm{~N}$ & $\%$ & $\mathrm{~N}$ & $\%$ \\
$<5\left(<13.6 \mathrm{Kg} / \mathrm{m}^{2}\right)$ & 3 & 2.22 & 1 & 0.75 & 4 & 2.96 \\
$5-85\left(13.6-17.3 \mathrm{Kg} / \mathrm{m}^{2}\right)$ & 38 & 28.15 & 41 & 30.39 & 79 & 58.52 \\
$85-95\left(17.3-18.5 \mathrm{Kg} / \mathrm{m}^{2}\right)$ & 12 & 8.88 & 18 & 13.33 & 30 & 22.22 \\
$>95\left(>18.5 \mathrm{Kg} / \mathrm{m}^{2}\right)$ & 13 & 9.62 & 9 & 6.66 & 22 & 16.3 \\
Total & 66 & 48.87 & 69 & 51.13 & 135 & 100 \\
\hline
\end{tabular}

Legenda: BMI - Indeks tjelesne mase, M - Dječaci, F- Djevojčice, N - Broj ispitanika 
U tabeli 1 data je struktura svih ispitanika po polu. $\mathrm{Na}$ osnovu vrednosti BMI sa povišenom tjelesnom masom $\left(17,3-18,5 \mathrm{Kg} / \mathrm{m}^{2}\right)$ bilo je 30 ispitanika $(22,22 \%)$, od toga 12 dječaka (8,88\%) i 18 djevojčica (13,33\%), a 22 ispitanika bilo je gojazno $\left(>18,5 \mathrm{Kg} / \mathrm{m}^{2}\right)$ što je $16,3 \%$, od čega 13 dječaka $(9,62 \%)$ i 9 djevojčica $(6,66 \%)$.

Tabela 2. Centralni i disperzioni parametri varijabli za procjenu gojaznosti i distribuciju tjelesne masti dječaka OŠ "Savo Ilić" i OŠ “Ratko Žarić"

\begin{tabular}{lccc}
\hline & N & Mean & S. D. \\
\hline BMI & 66 & 17.566 & 3.124 \\
WHR & 66 & .938 & .037 \\
WHtR & 66 & .473 & .052 \\
\hline
\end{tabular}

Legenda: BMI - Indeks tjelesne mase, WHR - Odnos opsega struka i kukova, WHtR - Odnos struka i visine, N - Broj ispitanika, Mean Aritmetička sredina. S.D. - Standardna devijacija

$\mathrm{Na}$ osnovu vrijednosti indeksa tjelesne mase (BMI), što je prikazano u tabeli 2 , može se konstatovati da se dječaci, koji su ušli u uzorak istraživanja, nalaze iznad 85. percentila, ali ne prelaze 95. percentil i shodno tome pripadaju kategoriji prekomjerne tjelesne težine. Rezultati varijable WHR nam jasno pokazuju da se dječaci nalaze ispod 1 , što je i normativ za njihov pol i uzrast i samim tim se nalaze ispod zone koja bi ih okarakterisala kao gojazne. Isto se može reći i za vrijednosti varijable WHtR u kojoj su rezultati ispod granice koja je postavljena na 0.5 . Na osnovu ovih statističkih parametara može se konstatovati da su dječaci koji su ušli u uzorak na samoj granici gojaznosti.

Tabela 3. Centralni i disperzioni parametri varijabli za procjenu gojaznosti i distribuciju tjelesne masti djevojčica OŠ "Savo Ilić" i OŠ "Ratko Žarić"

\begin{tabular}{lccc}
\hline & N & Mean & S. D. \\
\hline BMI & 66 & 17.388 & 2.720 \\
WHR & 66 & .943 & .043 \\
WHtR & 66 & .484 & .046 \\
\hline
\end{tabular}

Nakon analize dobijenih rezultata u tabeli 3, prema vrijednostima Indeksa tjelesne mase (BMI) može se konstatovati da djevojčice, koje su obuhvaćene ovim istraživanjem, pripadaju grupaciji koja se nalazi na samoj donjoj granici prekomjerne tjelesne težine. Ono što se takođe primjećuje jeste prekomjerna vrijednost $\mathrm{u}$ odnosu na postavljenu nor- $\mathrm{mu}(0.8)$, srednje vrijednosti rezultata varijable WHR, što bi djevojčice ove dvije škole okarakterisalo gojaznim. Nasuprot tome, vrijednosti varijable odnosa obima struka i tjelesne visine (WHtR) pokazuju da su blago ispod graničnih vrijednosti (0.5), koje bi ih okarakterisale gojaznim.

Tabela 4. Vrijednosti t-testa između aritmetičkih sredina varijabli za procjenu gojaznosti i distribucije tjelesne masti učenika OŠ "Savo Ilić" $i$ OŠ "Ratko Žarić" u odnosnu na pol

\begin{tabular}{lcccc}
\hline & Genger & N & t-test & Sig. \\
\hline BMI & M & 66 & .354 & .724 \\
& F & 69 &. & \\
WHR & M & 66 & -.766 & .445 \\
& F & 69 & & \\
WHtR & M & 66 & -1.345 & .181 \\
& F & 69 & & \\
\hline
\end{tabular}

Legenda: BMI - Indeks tjelesne mase, WHR - Odnos opsega struka i kukova, WHtR - Odnos struka i visine, M - Dječaci, F - Djevojčice, N - broj ispitanika, Sig. Značajnost razlike

$\mathrm{Na}$ osnovu dobijenih vrijednosti rezultata t-testa, koje su prikazane u tabeli 4 , može se primijetiti da ne postoje statistički značajne razlike između dječaka i djevojčica, na nivou značajnosti $\mathrm{p}<0.05$. Uvidom u numeričke vrijednosti testiranih varijabli, može se konstatovati da dječaci imaju veće numeričke vrijednosti u varijabli BMI, dok djevojčice imaju veće vrijednosti u varijablama WHR i WHtR, ali nijedna ne pokazuje statističku značajnost.

\section{Diskusija}

Rezultati ispitivanja pokazuju da je sa povišenom tjelesnom masom 30 ispitanika (22.22\%), dok su 22 ispitanika (16.3\%) gojazni. Znači da je opšta gojaznosti kod ispitivane đece $16.3 \%$. U istraživanju koje su sproveli Bukara-Radujkovic i Zdravkovic (2008) na uzorku đece i njihovih roditelja na teritoriji okoline Banja Luke, rezultati pokazuju da je gojaznost dječaka zastupljena na uzrastu od 6 do 10 godina 10.4\%, dok 
je sa povišenom tjelesnom masom bilo $15.7 \%$ ispitanika. $\mathrm{Na}$ istom uzrastu samo kod djevojčica gojaznost je bila zastupljena kod $7.8 \%$, dok je sa povišenom tjelesnom masom bilo $14.7 \%$ ispitanica. Krajem prošlog vijeka u SAD bilo je 13\% dece sa prekomjernom tjelesnom masom u uzrastu 6-11 godina, u Kini 11.3\% u uzrastu 6-9 godina, dok je u Brazilu istog uzrasta čak 17.4\% (Bukara-Radujkovic i Zdravkovic, 2008). Očigledno je da je opšta gojaznost kod ispitivane đece naše populacije od $16.3 \%$ krajnje zabrinjavajuća činjenica, što se može zakljčiti na osnovu pomenutog procenta koji je dobijen $\mathrm{u}$ našem istraživanju, a koji je veći nego u istraživanjima sa kojima se izvršila komparacija rezultata.

Što se tiče varijable WHR, u poređenju sa istraživanjem koje su sproveli Senbanjo, Oshikoya, Olutekunbi, \& Njokanma (2013), vrijednosti za dječake uzrasta 7 i 8 godina, koji su obuhvaćeni ovom studijom, relativno su približne vrijednostima koje su dobijene njihovim istraživanjem na uzorku ispitanika istog uzrasta. Naime, kod dječaka u njihovom istraživanju zabilježene su vrijednosti od 0.92 , dok su kod dječaka obuhvaćenim ovom studijom 0.93 , što je ispod graničnih vrijednosti centralne (abdominalne) gojaznosti. Što se tiče WHR vrijednosti kod djevojčica, u okviru istraživanja sprovedenog u Nigeriji, koja iznosi 0.90, a kod djevojčica obuhvaćene ovim istraživanjem 0.94 , vidimo veće vrijednosti centralne (abdominalne) gojaznosti, iako su i djevojčice u Nigeriji takođe prešle dozvoljenu granicu (0.8). Dakle, djevojčice generalno u oba istraživanja pokazuju veće vrijednosti centralne gojaznosti u okviru varijable WHR, nego što je to slučaj sa dječacima. Varijabla WHtR kod dječaka istog uzrasta, u istraživanju koje su sproveli Senbanjo i saradnici (2013), izražena je vrijednošću od 0.43 , dok je kod dječaka istog uzrasta u ovom istraživanju 0.47 . Što se tiče djevojčica u Nigeriji vrijednost WHtR je takođe 0.43 , što je ispod granične vrijednosti za procjenu centralne gojaznosti, što je i slučaj kod djevojčica obuhvaćenih ovim istraživanjem, čije su vrijednosti 0.48 .

Dakle, ovim istraživanjem smo dobili presjek stanja na pomenutom uzorku ispitanika i utvrdili da situacija nije za zanemariti. Na osnovu ovog saznanja, čim prije bi trebalo sprovesti još istraživanja na ovu temu i nakon toga sagledati cjelokupnu situaciju i dati određene savjete i smjernice ka rješavanju dobijene situacije, ukoliko bude pratila stanje dobijeno ovim istraživanjem. Dakle, što se tiče stanja dobijenog ovim istraživanjem može se preporučiti da treba, kao osnovno, u preventivne mjere protiv gojaznosti u djetinjstvu uključiti fizičku aktivnost, kao i promjenu faktora koji utiču na prekomjernu tjelesnu masu i gojaznost, a koji prvenstveno potiču iz socijalne sredine i edukacije roditelja (Despotović, Alekxopulos, Despotović, i Ilić, 2013). Da bi se preventivno djelovalo na problem sa kojim se suočava ispitivana populacija, potrebno je agresivno djelovati na smanjenje hipokinezije podizanjem svijesti o značaju fizičke aktivnosti. Kineziolozi i nastavnici bi trebali pravovremeno da detektuju ove probleme i roditeljima, kao i đeci, daju odgovarajuće savjete o pravilnom načinu života, kako bi održali status zdrave osobe sa normalnom tjelesnom težinom. Da bi se iznijeli neki konkretniji zaključci, u nekim narednim istraživanjima bi trebalo uzeti u obzir veći broj faktora, kao i veći broj ispitanika različitog uzrasta, a sve sa namjerom da se stane na put zdravstvenom problemu 21. vijeka.

Limitiranost ove studije se može ogledati u tome da uzorak obuhvaćen ovim istraživanjem nije dovoljno velik u odnosu na cjelokupnu populaciju. Samim tim, u narednim studijama ovog karaktera bi trebalo uključiti đecu i iz Sjeverne regije, kao i iz ruralnih i polu ruralnih područja, a na taj način bi sigurno dobili preciznije podatke za postavljeno istraživačko pitanje. Navedena konstatacija, svakako, ne umanjuje doprinos ove preliminarne studije, jer su u njoj iznešeni zaključci koji su izutetno bitni za dalji tok istraživanja na ovu temu u okviru pomenute populacije. Kao preporuka za buduća istraživanja ovog karaktera je da se, na nivou Crne Gore, uključe i roditelji ispitivane đece, odnosno da se izmjeri stepen gojaznosti roditelja đece koja su određena da uđu u uzorak istraživanja. Naime, smatra se da rezultati uhranjenosti roditelja koreliraju u velikoj mjeri sa rezultatima uhranjenosti đece, što je potvrđeno u studiji koju su sproveli Bukara-Radujkovic i Zdravkovic (2008), a to bi valjalo potvrditi i na teritoriji Crne Gore i samim tim skrenuti pažnju roditeljima da su oni jedni od glavnih odgovornih za stanje uhranjenosti njihove đece.

\section{Acknowledgements}

There are no acknowledgements.

\section{Conflict of Interest}

The authors declare that there are no conflicts of interest.

Received: 8 January 2019 | Accepted: 13 March 2019 | Published: 19 April 2019

\section{References}

Bjelica, D. (2006). Teorijske osnove tjelesnog i zdrastvenog obrazovanja. Podgorica: Crnogorska sportska akademija.

Bukara-Radujkovic G. i Zdravkovic, D. (2008). Determinante gojaznosti kod dece i adolescenata. Srpski Arhiv za Celokupno Lekarstvo, 136(1-2), 22-7.

de Onis, M., Blossner, M., \& Borghi, E. (2010). Global prevalence and trends of overweight and obesity among preschool children. The American Journal of Clinical Nutrition, 92, 1257-64.

Despotović, M., Alekxopulos, H., Despotović, M., \& llić, B. (2013). Stanje uhranjenosti dece predškolskog uzrasta. Medicinski časopis, 47(2), 62-8.

Fung, W. (2009). Early childhood malnutrition and adult obesity: Evidence from the 1959-61 China famine. Harvard University, Mimeograph. Preuzeto sa: http://citeseerx.ist.psu.edu/viewdoc/summary?doi=10.1.1.189.1517

Gortmaker, S. L., Dietz, W. H. Jr., Sobol, A. M., \& Wehler, C. A. (1987). Increasing obesity in the United States. American journal of diseases of children, 141, 535-40.

Gigante, D. P., Victora, C. G., Horta, B. L., \& Lima, R.C. (2007). Undernutritionin early life and body composition of adolescent malesfrom a birth cohort study. British Journal of Nutrition, 97(5), 949-54.

Lobstein, T., Baur, L., \& Uauy, R. (2004). IASO International Obesity Task Force. Obesity in children and young people: a crisisin public health. Obesity Reviews, 5(1), 4-85

Masanovic, B., Vukotic, M., Bjelica, D., \& Popovic, S. (2018). Describing Physical Activity Profile of Older Montenegrin Males Using the International Physical Activity Questionnaire (IPAQ). In Book of Abstracts 15th International Scientific Conference on Transformation Process in Sport "Sport Performance" (61). Podgorica: Montenegrin Sports Academy.

Must, A., Jacques, P. F., Dallal, G. E., Bajema, C. Y., \& Dietz, W. H. (1992). Long term morbidity and mortality of overweight adolescents. The New England Journal of Medicine, 327, 1350-5.

McCarthy, H. D., \& Ashwell, M. (2006). A study of central fatnessusing waist-toheight ratios in UK children and adolescents over two decades supports the simple message-'keep your waist circumference to less than half your height'. International Journal of Obesity, 30, 988-92.

Palloni, A., McEniry, M., D avila, A. L., \& Gurucharri, A. G. (2005). The influence of early conditions on health status among elderly Puerto Ricans. Social biology, 52(3-4), 132-63.

Popović, S., Bjelica, D., Mašanović, B., \& Vukotić, M. (2018). Describing physical activity profile of young Montenegrin females using the international physical activity questionnaire (IPAQ). In Proceedings World Congress of Performance Analysis of Sport XII (344). Opatija: International Society of Performance Analysis of Sport.

Popovic, S., Bjelica, D., Vukotic, M., \& Masanovic, B. (2018). Describing Physical Activity Profile of Older Montenegrin Females Using the International Physical Activity Questionnaire (IPAQ). In Book of Abstracts 15th International Scientific Conference on Transformation Process in Sport "Sport Performance" (60-61). Podgorica: Montenegrin Sports Academy. 
Power, C., Lake, J. K., \& Cole, T. J. (1997). Measurement and long-term health risks of child and adolescent fatness. International Journal of Obesity, 21 507-26.

Schroeder, D. G., Martorell, R., \& Flores, R. (1999). Infant and childgrowth and fatness and fat distribution in Guatemalan adults. American Journal of Epidemiology, 149(2), 177-85.

Senbanjo, I. O., Oshikoya, K. A., Olutekunbi, O. A., \& Njokanma, O.F. (2013). Body Fat Distribution of Children and Adolescents in Abeokuta, Southwest Nigeria. American Journal Physical Anthropology, 150(4), 647-54. doi: 10.1002/ajpa.22241

Srinivasan, S. R., Bao, W., Wattigney, W. A., \& Berenson, G. S. (1996). Adolescent overweight is associated with adult overweight and related multiple cardiovascular risk factors. Metabolism, 45(2), 235-40.
Uauy, R., Kain, J., \& Corvalan, C. (2011). How can the Developmental Origins of Health and Disease $(\mathrm{DOHaD})$ hypothesis contributeto improving health in developing countries? The American Journal of Clinical Nutrition, 94(6), 1759-64.

Vasiljević, I., Bjelica, D., Popović, S. i Gardašević, J. (2015). Analysis of nutrition of preschool-age and younger school-age boys and girls. Journal of Physical Education and Sport, 15(3), 426-28.

Wang, Y.F., \& Lobstein, T. (2006). Worldwide trends in childhood overweight and obesity. International Journal of Pediatric Obesity, 1(1), 11-25.

World Health Organization expert committee. (1995). Physical status, the use and interpretation of anthropometry. Geneva: World Health Organization. 